\title{
Oxidation of cycloalkanes catalysed by $N$-hydroxyimides in supercritical carbon dioxide
}

\author{
Dawid Lisicki $^{1} \cdot$ Beata Orlińska ${ }^{1}$ (i)
}

Received: 15 October 2018 / Accepted: 24 April 2019 / Published online: 24 September 2019

(c) The Author(s) 2019

\begin{abstract}
This paper reports cyclopentane, cyclohexane and cyclooctane oxidation in the presence of $\mathrm{N}$-hydroxyphthalimide or 4-dodecyloxycarbonyl- $N$-hydroxyphthalimide in combination with $\mathrm{Co}$ (II) and $\mathrm{Fe}$ (II) salts using $\mathrm{O}_{2} / \mathrm{CO}_{2}$ mixture $\left(0.5 \mathrm{MPa} \mathrm{O}_{2}\right.$, 9.5 $\mathrm{MPa} \mathrm{CO}_{2}$ ). The studies demonstrated that the application of $\mathrm{scCO}_{2}$ in cyclohexane and cyclooctane oxidation processes results in higher conversion and yield of respective ketone and alcohol in comparison to processes performed using air under pressure $(0.7 \mathrm{MPa})$.
\end{abstract}

Keywords Oxidation $\cdot \mathrm{N}$-Hydroxyphthalimide $\cdot$ Carbon dioxide $\cdot$ Cyclopentane $\cdot$ Cyclohexane $\cdot$ Cyclooctane

\section{Introduction}

Carbon dioxide can be used as an alternative solvent or reagent. Usage of $\mathrm{CO}_{2}$ as a solvent is very promising because it is not toxic, it is not corrosive, its critical parameters are mild (304.2 K, 7.38 MPa) and it can be easily separated from a post-reaction mixture by modifying the temperature or pressure (Mayadevi 2012). Its use in aerobic oxidation reactions is of particular note; carrying out these strongly exothermic processes in a $\mathrm{CO}_{2}$ environment is very safe because of its excellent heat transfer and conductive properties. Moreover, $\mathrm{CO}_{2}$ does not undergo subsequent oxidation reactions, which in the case of using organic solvents, is responsible for huge solvent losses. These features make its usage even more attractive in modern chemical processes that are in accordance with the principles of 'green chemistry'.

The oxidations of cyclopentane (Suzuki et al. 2007), cyclohexane (Ishii et al. 1996; Iwahama et al. 1998), cyclooctane (Mitra et al. 2013) and cyclodecane (Staudt et al. 2013) to the desired alcohols, ketones or dicarboxylic acids have been reported. The crucial issue was to achieve high selectivity to desired products. The most important in terms of tonnage of product is the oxidation of cyclohexane

Beata Orlińska

beata.orlinska@polsl.pl

1 Department of Chemical Organic Technology and Petrochemistry, Silesian University of Technology, Krzywoustego 4, 44-100 Gliwice, Poland to the cyclohexanone: cyclohexanol (K:A) mixture (global production equals 7 million $\mathrm{t} / \mathrm{year}$ ), which in industry is performed using air, solvent-free conditions and a Co(II) and/or Fe(II) salt $\left(0.5-2.0 \mathrm{MPa}, 140-180^{\circ} \mathrm{C}\right)$. To achieve high selectivity (ca. 75-85\%) to K:A mixture, the process is performed at a very low conversion (5-7\%) (Krzysztoforski et al. 1986). Therefore, new catalysts and methods to enhance the process are an active area of research.

In recent years, the oxidations of cycloalkanes in the presence of $\mathrm{N}$-hydroxyphthalimide (NHPI) and transition metal salts, mainly Co compounds, have been described (Ishii et al. 1996). The activity of NHPI in the oxidations of hydrocarbons is related to the generation of the phthalimide $N$-oxyl radical (PINO) in the system, which can efficiently abstract a hydrogen atom from the oxidized compound (Fig. 1). The PINO radical is generated in situ by peroxyl radicals as well as transition metals salts such as Co(II) (Chen et al. 2014).

The application of NHPI in the oxidation of cyclic hydrocarbons allows the reaction to be run at a considerably lower temperature and causes an increase in selectivity to the desired products (Hermans et al. 2007). However, due to limited solubility of NHPI in hydrocarbons, solvents such as acetic acid $(\mathrm{AcOH})$, acetonitrile or benzonitrile are used. For example, the oxidation of cyclohexane in $\mathrm{AcOH}$ at $100{ }^{\circ} \mathrm{C}$ in the presence of $\mathrm{Co}$ (II) was not observed (Ishii et al. 1996). Under the same conditions in the presence of NHPI/Co(II) system, the cyclohexane conversion was $46 \%$ and the main reaction products were cyclohexanone and adipic acid, obtained with selectivities of 32 and $38 \%$, resp. 
Fig. 1 Mechanism of the oxidation of cyclohexane using NHPI

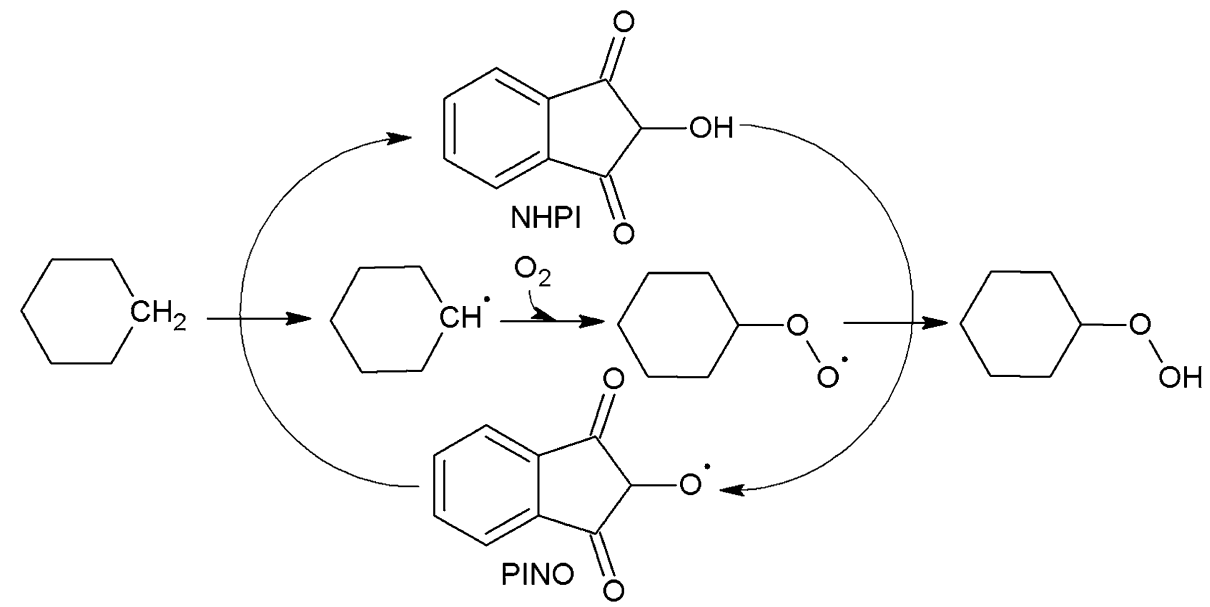

Interestingly, the type of the catalyst system and the solvent makes it possible to obtain a particular product with higher selectivity. For example, with the NHPI/Co(III) system in acetonitrile, at a low temperature of $75^{\circ} \mathrm{C}$, the main product of cyclohexane oxidation (conversion of 13\%) is cyclohexanone, obtained with $78 \%$ selectivity. In contrast, with the NHPI/Mn(III) system, in acetic acid, at $100{ }^{\circ} \mathrm{C}$, the main product is adipic acid (selectivity $77 \%$, conversion $44 \%$ ). Oxidizing cyclooctane, in the presence of NHPI/Co(III), a mixture of cyclooctanone, cyclooctane-1,4-dione and octanedioic acid was obtained, and the products were generated with selectivities of $50 \%, 16 \%$ and $16 \%$, respectively and 93\% conversion (Ishii et al. 1996).

Attempts were made to eliminate solvent from the NHPIcatalysed oxidation of hydrocarbons. Oxidations of cyclopentane, cyclohexane and cyclooctane were carried out under solvent-free conditions using lipophilic derivatives of NHPI (Sawatari et al. 2001) or NHPI (Hermans et al. 1996) supported on a solid carrier in combination with a $\mathrm{Co}(\mathrm{II})$ or $\mathrm{Mn}$ (II) salt. For example, by using lipophilic 4-dodecyloxycarbonyl- $N$-hydroxyphthalimide (NHPI- $\left.\mathrm{C}_{12}\right) / \mathrm{Co}$ (II)/Mn(II), at $100{ }^{\circ} \mathrm{C}$, after $14 \mathrm{~h}$ conversion of $1.6,4.5,8.9$ and $11.4 \%$ were obtained for cyclopentane, cyclohexane, cyclooctane and cyclododecane resp. The main products were respective alcohols (in yield of $0.2,1.3,2.67 .2 \%$, resp.) and ketones $(0.7,2.8,6.1,7.2 \%$, resp.). Using the NHPI/Co(II)/Mn(II) system, the authors obtained significantly lower conversions of cycloalkanes and productivities of alcohols and ketones as compared to the reaction for lipophilic NHPI-C12. When NHPI immobilized on silica was applied in the oxidation of cyclohexane, a maximum conversion of $4.5 \%$ was obtained. The products contained cyclohexanol, cyclohexanone, adipic acid and glutaric acid.

To date, limited number of studies on the oxidation of cyclic hydrocarbons in supercritical carbon dioxide have been reported. In previous report (Kerry et al. 2007), the oxidation of cyclohexane using NHPI/Co(II)/Mn(II) in $\mathrm{scCO}_{2}$ was described $\left(155^{\circ} \mathrm{C}, 2.0 \mathrm{MPa} \mathrm{O}_{2}^{-}, 14.0 \mathrm{MPa} \mathrm{CO}_{2}, 8 \mathrm{~h}\right)$. It was determined that it is necessary to add polar $\mathrm{AcOH}$ to the system, and without this additive, the reaction did not proceed. The major product of the reaction was adipic acid, which was produced with $95 \%$ of selectivity from $55 \%$ conversion of the raw material. An oxidation of cyclooctane with oxygen in $\mathrm{scCO}_{2}$ in the presence of acetic aldehyde has also been described (Theyssen and Leitner 2002). For example, when the process was carried out at $52{ }^{\circ} \mathrm{C}$ for $26 \mathrm{~h}$, $27.6 \%$ cyclooctane conversion was achieved, and the postreaction mixture mainly contained cyclooctanone, cyclooctanol, and cyclooctane-1,4-dione, which were obtained in selectivities of $66.9 \%, 8.5 \%$ and $7.8 \%$, respectively. The use of $\mathrm{scCO}_{2}$ in the two works described above, allowed significant improvements in the selectivities of the reactions for the generation of adipic acid or cyclooctane-1,4-dione.

\section{Experimental}

\section{Materials}

Cyclopentane, cyclohexane, cyclooctane, $N$-hydroxyphthalimide, $\mathrm{Co}$ (II) 2-ethylhexanoate and $\mathrm{Fe}$ (II) 2-ethylhexanoate were commercially available. 4-Dodecyloxycarbonyl- $N$-hydroxyphthalimide was prepared according the known procedure (Kasperczyk et al. 2014).

\section{General procedure of cycloalkane oxidation using air under pressure}

Cyclic alkane $(20 \mathrm{ml})$ and $\mathrm{Co}(\mathrm{II})$ and $\mathrm{Fe}(\mathrm{II})$ 2-ethylhexanoates $(0.1 \mathrm{ppm})$ were placed in a $100-\mathrm{ml}$ pressure reactor made of Hastelloy C-276 steel. The oxidation was carried out with air at $0.7 \mathrm{MPa}$ for $1 \mathrm{~h}$ at $150{ }^{\circ} \mathrm{C}$ and $1000 \mathrm{rpm}$. 
After the reaction was finished the mixture was cooled to $5{ }^{\circ} \mathrm{C}$ and the pressure was slowly reduced.

\section{General procedure of cycloalkane oxidation using oxygen in supercritical $\mathrm{CO}_{2}$}

Cyclic alkane $(20 \mathrm{ml})$ and $\mathrm{Co}(\mathrm{II})$ and $\mathrm{Fe}(\mathrm{II})$ 2-ethylhexanoates $(0.1 \mathrm{ppm})$ were placed in a $100-\mathrm{ml}$ pressure reactor made of Hastelloy C-276 steel. After heating the reaction mixture to $60{ }^{\circ} \mathrm{C}$, liquid carbon dioxide metered with a Jasco PU-2080- $\mathrm{CO}_{2}$ pump was added. After reaching $150{ }^{\circ} \mathrm{C}$ and the specific $\mathrm{CO}_{2}$ pressure, an appropriate amount of oxygen was introduced into the reactor. The oxidation was carried out for $1 \mathrm{~h}$ at $150{ }^{\circ} \mathrm{C}$ and $1000 \mathrm{rpm}$. After the reaction was finished the mixture was cooled to $5{ }^{\circ} \mathrm{C}$ and the pressure was slowly reduced.

\section{Analysis of the post-reaction mixture}

The contents of the corresponding ketone and alcohol in the oxidation product mixture were determined by gas chromatography using an Agilent Technologies 7890C chromatograph equipped with an FID and an autosampler (ZB-5HT column $30 \mathrm{~m} \times 0.25 \mathrm{~mm} \times 0.25 \mu \mathrm{m}$, helium as the carrier gas, injector temperature: $200{ }^{\circ} \mathrm{C}$, detector temperature: $250{ }^{\circ} \mathrm{C}$ ). Toluene was used as an internal standard.

\section{Determination of the acid number}

A $1 \mathrm{~g}$ portion of the sample to be analysed was weighed with a precision of $0.00001 \mathrm{~g}$ and was placed in a $100-\mathrm{ml}$ conical flask, and $25 \mathrm{ml}$ of ethanol neutralized with $\mathrm{NaOH}$ was added. The contents of the flask was titrated with $0.01 \mathrm{M}$ $\mathrm{NaOH}$ in the presence of phenolphthalein.

\section{Results and discussion}

Herein, the oxidations of cyclic alkanes by oxygen using NHPI or its lipophilic derivative NHPI- $\mathrm{C}_{12}$ in combination with transition metals salts as the catalysts in $\mathrm{CO}_{2}$ under pressure was studied. Cyclopentane, cyclohexane and cyclooctane were used as raw materials. A mixture of lipophilic salts, namely, the 2-ethylhexanoates of $\mathrm{Co}$ (II) and $\mathrm{Fe}(\mathrm{II})(0.1 \mathrm{ppm})$, was used as the co-catalysts. Previous reports have suggested that these salts dissolve well in non-polar systems. Additionally, when an Fe(II) salt is used in combination with a $\mathrm{Co}$ (II) salt, the ratio of the ketone to alcohol products increases. Ketones are the more valuable products because they are more applicable in the direct synthesis of the corresponding dicarboxylic acid or lactam, e.g., adipic acid and $\varepsilon$-caprolactam in the case of cyclohexanone. For the comparison, reactions without $\mathrm{CO}_{2}$ were also carried out. In these cases, air was used as the oxidizing agent instead of oxygen for safety reasons.

As expected, the main products obtained in studied reactions under the applied conditions are the corresponding ketones and alcohols (K:A). Dicarboxylic acids, products of the over-oxidation of $\mathrm{K}: \mathrm{A}$, were formed in small amounts. The conversion and yields of $\mathrm{K}$ :A were determined by GC and the total content of acids was determined based on acid number (AN) of the post-reaction mixtures.

First, the effects of NHPI and its lipophilic derivative NHPI- $\mathrm{C}_{12}$ were studied in the oxidation of cyclohexane using air or an $\mathrm{O}_{2} / \mathrm{CO}_{2}$ mixture (Table 1, entries 5-20). It was determined that NHPI positively influenced the degree of conversion of the raw material only in the reactions that were carried out in $\mathrm{CO}_{2}$ under pressure (entries 5-12). NHPI is very poorly soluble in cyclohexane (its solubility is lower than $0.00069 \mathrm{~g}$ in $100 \mathrm{~g}$ of cyclohexane at $150{ }^{\circ} \mathrm{C}$ under $0.8 \mathrm{MPa}$ of pressure). The presence of non-polar $\mathrm{CO}_{2}$ is not expected to influence the solubility of NHPI in the studied systems. In the presence of $\mathrm{scCO}_{2}$, the contact between the solid NHPI, gaseous oxygen and hydrocarbon is expected to be more effective.

The catalytic effects of lipophilic NHPI- $\mathrm{C}_{12}$ were observed in oxidations performed both with and without $\mathrm{CO}_{2}$ (entries 13-20). As expected, noticeably higher degrees of conversion were obtained in reactions carried out in the presence of NHPI-C $\mathrm{C}_{12}$ than in those with NHPI under the same conditions. Depending on the amount used, lipophilic NHPI-C ${ }_{12-}$ most likely dissolves completely or in large part into the reaction mixture. We believe that the conversion decrease in the oxidation of cyclohexane when increasing amounts of NHPI- $\mathrm{C}_{12}$ were used (from 0.1 to $1 \%$ mol.) in the absence of $\mathrm{CO}_{2}$ (entries 15,16) may be a result of the negative influence of the presence of solid, non-dissolved catalyst on the reaction. We observed such an effect before in the oxidations of other hydrocarbons (Kasperczyk et al. 2014). In the oxidation of cyclohexane using NHPI- $\mathrm{C}_{12}$ under $\mathrm{CO}_{2}$, the yield of products increased as the amount of catalyst increased over the whole tested range of catalyst loadings $(0.05-1 \mathrm{~mol} \%$, entries $17-20)$. This result indicates that $\mathrm{scCO}_{2}$ has a positive influence on the solubility of lipophilic NHPI- $\mathrm{C}_{12}$ and improves the contact between the catalyst and reagents.

The positive effects of NHPI and NHPI- $\mathrm{C}_{12}$ on the ketone/alcohol ratio were observed for processes carried out in supercritical carbon dioxide as well as those conducted without $\mathrm{CO}_{2}$. This is most likely caused by the catalytic effect of the applied $N$-hydroxyimides on the oxidation of cyclohexanol to cyclohexanone, which has been described previously (Iwahama et al. 1998). Researchers 
Table 1 Aerobic oxidation of cyclic alkanes in the presence of an NHPI/Co(II)/Fe(II) system in supercritical $\mathrm{CO}_{2}$

\begin{tabular}{|c|c|c|c|c|c|c|c|c|c|c|}
\hline \multirow{2}{*}{ Entry } & \multirow{2}{*}{ Cycloalkane } & \multirow{2}{*}{\multicolumn{2}{|c|}{$\begin{array}{l}\text { Catalyst } \\
{[\% \mathrm{~mol}]}\end{array}$}} & \multirow{2}{*}{ System $^{\mathrm{a}}$} & \multirow{2}{*}{$\begin{array}{c}\text { Conv }^{\mathrm{b}} \\
{[\%]}\end{array}$} & \multicolumn{3}{|c|}{ Yield $^{\mathrm{c}}[\mathrm{mol} \%]$} & \multirow{2}{*}{$\mathrm{K}: \mathrm{A}^{\mathrm{e}}$} & \multirow{2}{*}{$\begin{array}{c}\mathrm{AN}^{\mathrm{f}} \\
{[\mathrm{mgKOH} / \mathrm{g}]}\end{array}$} \\
\hline & & & & & & Alcohol & Ketone & $\Sigma^{\mathrm{d}}$ & & \\
\hline 1 & & NHPI & 0.1 & Air & 1.8 & 0.8 & 0.7 & 1.5 & 0.9 & 2.6 \\
\hline 2 & & NHPI & 0.1 & $\mathrm{O}_{2} / \mathrm{scCO}_{2}$ & 1.1 & 0.4 & 0.6 & 1.0 & 1.5 & 4.6 \\
\hline 3 & & NHPI-C 12 & 0.1 & Air & 2.8 & 1.0 & 1.3 & 2.3 & 1.3 & 3.1 \\
\hline 4 & & NHPI-C 12 & 0.1 & $\mathrm{O}_{2} / \mathrm{scCO}_{2}$ & 2.0 & 0.5 & 1.4 & 1.9 & 2.8 & 7.6 \\
\hline 5 & & NHPI & - & Air & 4.0 & 1.6 & 1.6 & 3.2 & 1.0 & 1.9 \\
\hline 6 & & NHPI & 0.05 & Air & 3.8 & 1.3 & 1.9 & 3.2 & 1.5 & 1.7 \\
\hline 7 & & NHPI & 0.1 & Air & 3.8 & 1.2 & 1.9 & 3.1 & 1.6 & 2.3 \\
\hline 8 & & NHPI & 1 & Air & 3.9 & 1.4 & 1.8 & 3.2 & 1.3 & 3.2 \\
\hline 9 & & NHPI & - & $\mathrm{O}_{2} / \mathrm{scCO}_{2}$ & 6.0 & 2.6 & 2.8 & 5.4 & 1.1 & 6.2 \\
\hline 10 & & NHPI & 0.05 & $\mathrm{O}_{2} / \mathrm{scCO}_{2}$ & 4.0 & 1.5 & 2.2 & 3.7 & 1.5 & 9.0 \\
\hline 11 & & NHPI & 0.1 & $\mathrm{O}_{2} / \mathrm{scCO}_{2}$ & 10.2 & 3.9 & 5.7 & 9.6 & 1.5 & 5.0 \\
\hline 12 & & NHPI & 1 & $\mathrm{O}_{2} / \mathrm{scCO}_{2}$ & 1.0 & 4.4 & 4.8 & 9.3 & 1.1 & 8.4 \\
\hline 13 & & $\mathrm{NHPI} \mathrm{C}_{12}$ & - & Air & 4.0 & 1.6 & 1.6 & 3.2 & 1.0 & 1.9 \\
\hline 14 & & $\mathrm{NHPI} \mathrm{C}_{12}$ & 0.05 & Air & 6.0 & 2.5 & 2.3 & 4.8 & 0.9 & 3.7 \\
\hline 15 & & $\mathrm{NHPI}^{-\mathrm{C}_{12}}$ & 0.1 & Air & 6.8 & 2.8 & 2.8 & 5.6 & 1.0 & 3.3 \\
\hline 16 & & $\mathrm{NHPI}^{-\mathrm{C}_{12}}$ & 1 & Air & 4.9 & 1.2 & 2.7 & 3.9 & 2.3 & 9.9 \\
\hline 17 & & $\mathrm{NHPI}^{-\mathrm{C}_{12}}$ & - & $\mathrm{O}_{2} / \mathrm{scCO}_{2}$ & 6.0 & 2.6 & 2.8 & 5.4 & 1.1 & 6.2 \\
\hline 18 & & $\mathrm{NHPI}_{-\mathrm{C}_{12}}$ & 0.05 & $\mathrm{O}_{2} / \mathrm{scCO}_{2}$ & 6.8 & 2.7 & 3.5 & 6.2 & 1.3 & 5.6 \\
\hline 19 & & $\mathrm{NHPI}^{-\mathrm{C}_{12}}$ & 0.1 & $\mathrm{O}_{2} / \mathrm{scCO}_{2}$ & 12.0 & 4.1 & 6.9 & 11.0 & 1.7 & 7.7 \\
\hline 20 & & $\mathrm{NHPI} \mathrm{C}_{12}$ & 1 & $\mathrm{O}_{2} / \mathrm{scCO}_{2}$ & 15.5 & 5.3 & 9.4 & 14.7 & 1.8 & 17.5 \\
\hline 21 & & NHPI & 0.1 & Air & 11.2 & 4.9 & 4.5 & 9.4 & 0.9 & 2.6 \\
\hline 22 & & NHPI & 0.1 & $\mathrm{O}_{2} / \mathrm{scCO}_{2}$ & 39.1 & 12.0 & 20.1 & 32.1 & 1.7 & 12.1 \\
\hline 23 & & $\mathrm{NHPI}^{-\mathrm{C}_{12}}$ & 0.1 & Air & 11.8 & 5.4 & 4.7 & 10.1 & 0.9 & 2.1 \\
\hline 24 & & $\mathrm{NHPI} \mathrm{C}_{12}$ & 0.1 & $\mathrm{O}_{2} / \mathrm{scCO}_{2}$ & 50.2 & 13.2 & 27.3 & 40.5 & 2.1 & 14.3 \\
\hline
\end{tabular}

Cycloalkane - $20 \mathrm{ml}, \mathrm{Co}$ (II) 2-ethylhexanoate-0.1 ppm, Fe(II) 2-ethylhexanoate- $0.1 \mathrm{ppm}, 150{ }^{\circ} \mathrm{C}, 1 \mathrm{~h}$

${ }^{\mathrm{a}}$ Air $0.7 \mathrm{MPa}$ or $\mathrm{O}_{2} / \mathrm{CO}_{2}$ 0.5/9.5 $\mathrm{MPa}$

${ }^{\mathrm{b}}$ Conversion $=\Sigma n$ (product, GC) $/ n$ (hydrocarbon, loaded)

${ }^{\mathrm{c}}$ Yield mol \%, the maximum standard uncertainty is 0.09

${ }^{\mathrm{d}}$ Total yield mol \% of alcohole and ketone

${ }^{\mathrm{e}}$ Ketone to alcohole ratio (mol \%/mol \%)

${ }^{\mathrm{f}}$ Acid number, The maximum standard uncertainty is 0.3

demonstrated the catalytic impact of the NHPI/Co(III) system in the reaction of oxidation of alcohols (such as: 2-octanol, 1-octanol, 1-hexanol, 2-methyl-1-pentanol, cyclohexanol, cyclooctanol) and diols (such as: cyklohexyl-1,2-diol, cyclohexyl-1,4-diol, pentyl-1,5-diol) to the corresponding carbonyl compounds (Iwahama et al. 1998).

It was determined that NHPI and NHPI- $\mathrm{C}_{12}$ can detrimentally increase the acid value to a small degree. The highest observed acid value ( $17.5 \mathrm{mg} \mathrm{KOH} / \mathrm{g}$, entry 20 ) means that the total yield of dicarboxylic acids, in this case adipic, glutaric and succinic acids, was approximately $1.2 \mathrm{~mol} \%$ (2.2 wt $\%$ ).

Next, the oxidations of cyclopentane and cyclooctane were carried out under similar conditions (entries 1-4 and 21-24). Loadings of $0.1 \mathrm{~mol} \% \mathrm{~N}$-hydroxyimides, NHPI or NHPI- $\mathrm{C}_{12}$ were used because in the case of the oxidation of cyclohexane, further increases in the catalyst loading 
Table 2 Aerobic oxidation of cyclohexane in the presence of NHPI- $\mathrm{C}_{12} / \mathrm{Co}(\mathrm{II}) / \mathrm{Fe}(\mathrm{II})$ system in supercritical $\mathrm{CO}_{2}$

\begin{tabular}{|c|c|c|c|c|c|c|c|c|c|c|}
\hline \multirow[t]{2}{*}{ Entry } & \multirow[t]{2}{*}{ Temp $\left[{ }^{\circ} \mathrm{C}\right]$} & \multirow[t]{2}{*}{$\mathrm{O}_{2}[\mathrm{MPa}]$} & \multirow[t]{2}{*}{$\mathrm{scCO}_{2}[\mathrm{MPa}]$} & \multirow[t]{2}{*}{ Time $[\mathrm{h}]$} & \multirow[t]{2}{*}{ Conv $[\%]^{\mathrm{a}}$} & \multicolumn{3}{|c|}{ Yield [mol \% $]^{\mathrm{b}}$} & \multirow[t]{2}{*}{$\mathrm{K}: \mathrm{A}^{\mathrm{d}}$} & \multirow{2}{*}{$\begin{array}{l}\mathrm{AN} \\
{[\mathrm{mgKOH} /} \\
\mathrm{g}]^{\mathrm{e}}\end{array}$} \\
\hline & & & & & & Alcohol & Ketone & $\Sigma^{\mathrm{c}}$ & & \\
\hline 1 & 120 & 5 & 95 & 1 & 0.8 & 0.1 & - & 0.1 & - & 1.7 \\
\hline 2 & 130 & 5 & 95 & 1 & 2.0 & 0.7 & 1.1 & 1.8 & 1.6 & 2.1 \\
\hline 3 & 140 & 5 & 95 & 1 & 6.6 & 1.5 & 4.5 & 6.0 & 3.0 & 2.8 \\
\hline 4 & 150 & 5 & 95 & 1 & 6.8 & 2.7 & 3.5 & 6.2 & 1.3 & 5.6 \\
\hline 5 & 150 & 10 & 95 & 1 & 7.1 & 1.3 & 4.7 & 6.0 & 3.6 & 7.6 \\
\hline 6 & 150 & 15 & 95 & 1 & 7.0 & 1.1 & 4.6 & 5.7 & 4.2 & 7.4 \\
\hline 7 & 150 & 5 & 105 & 1 & 5.6 & 3.0 & 2.3 & 5.3 & 0.8 & 7.0 \\
\hline 8 & 150 & 5 & 85 & 1 & 6.7 & 2.2 & 3.4 & 5.6 & 1.5 & 5.8 \\
\hline 9 & 150 & 5 & 95 & 1.5 & 9.1 & 1.8 & 2.3 & 4.1 & 1.3 & 3.9 \\
\hline 10 & 150 & 5 & 95 & 2 & 11.2 & 1.1 & 1.6 & 2.7 & 1.5 & 5.7 \\
\hline 11 & 150 & 5 & 95 & 0.5 & 3.0 & 1.5 & 1.5 & 3.0 & 1.0 & 2.0 \\
\hline $12^{\mathrm{f}}$ & 150 & 5 & 95 & 1 & 3.0 & 1.1 & 1.2 & 2.3 & 1.1 & 9.0 \\
\hline $13^{\mathrm{g}}$ & 150 & 5 & 95 & 1 & 0.5 & 0.3 & 0.1 & 0.4 & 0.3 & 22.2 \\
\hline
\end{tabular}

Cyclohexane-20 ml, Co(II) 2-ethylhexanoate-0.1 ppm, Fe(II) 2-ethylhexanoate-0.1 ppm, 4-dodecyloxycarbonyl- $N$-hydroxyphthalimide $0.05 \% \mathrm{~mol}, 150{ }^{\circ} \mathrm{C}, 1 \mathrm{~h}$

${ }^{\mathrm{a}}$ Conversion $=\Sigma n$ (product, GC) $/ n$ (hydrocarbon, loaded)

${ }^{b}$ Yield mol \%, the maximum standard uncertainty is 0.09

${ }^{\mathrm{c}}$ Total yield mol $\%$ of alcohole and ketone

${ }^{\mathrm{d}}$ Ketone to alcohole ratio (mol \%/mol \%)

${ }^{\mathrm{e}}$ Acid number, the maximum standard uncertainty is 0.3

${ }^{\mathrm{f}}$ Cyclohexane $-5 \mathrm{ml}$

${ }^{\mathrm{g}}$ Cyclohexane $-1 \mathrm{ml}$

resulted in minor increases in K:A yield and unfavourable increases in the acid number. When less-reactive cyclopentane was used as the starting material, the use of $\mathrm{scCO}_{2}$ only led to an increase in the ketone/alcohol ratio and an undesirable increase in the acid number. The best results were obtained in the case of the oxidation of cyclooctane (entries 21-24). Significant increases of conversion and the yields of cyclooctanone and cyclooctanol were achieved when $N$-hydroxyimides-catalysed reactions were performed under $\mathrm{scCO}_{2}$.

The effect of temperature, pressure of $\mathrm{O}_{2}$ or $\mathrm{CO}_{2}$ and time of reaction on the cyclohexane oxidation in the presence of NHPI-C ${ }_{12} / \mathrm{Co}(\mathrm{II}) / \mathrm{Fe}$ (II) system has been also established (Table 2).

It has been shown that in the studied range of temperature $120-150{ }^{\circ} \mathrm{C}$ the cyclohexane conversion increased from 0.8 to $6.8 \%$. Simultaneously AN of products was also slightly increased. It has been observed that increase of oxygen pressure from 5 to $15 \mathrm{MPa}$ influenced the subsequent reactions: desired alcohol oxidation to ketone (K:A increase) but also undesired over-oxidation to acids (AN increase). In contrast, when $\mathrm{CO}_{2}$ pressure increased the rates of alcohol to ketone oxidation as well as over-oxidation decreased, as an effect of system dissolution.
The studied reactions were performed in two-phase systems. It is known that $\mathrm{CO}_{2}$ is completely miscible with oxygen under supercritical conditions, but substrates did not dissolve entirely in $\mathrm{scCO}_{2}$ under applied conditions (additionally, the system could contain a solid particles of an insoluble catalyst). However, obtained results indicated that the use of $\mathrm{scCO}_{2}$ in 2-phase system caused the significant increase of conversion of cyclohexane and cyclooctane in oxidation reactions using oxygen and NHPI or NHPI- $\mathrm{C}_{12}$ and $\mathrm{Co}(\mathrm{II}) / \mathrm{Fe}$ (II) as catalysts. The positive influence of the use of $\mathrm{scCO}_{2}$ in two-phase system on the oxidation reaction rate by enhancement of mass transfer rate has been previously reported (Beckman 2003).

The rate of oxidation reaction with oxygen in $\mathrm{scCO}_{2}$ in single-phase system, when catalyst is soluble, is usually higher in comparison to two-phase system, because reaction proceeds in kinetically controlled regime instead of transport controlled regime. However, in order to obtain single-phase system the amount of cycloalkane must be reduced or significantly higher pressure is needed which adversely affects the process economy (Beckman 2003). In our study, the amount of cyclohexane was reduced from 20 to $1 \mathrm{ml}$ (Table 2, entry 13). Unfortunately the conversion obtained was very low. It 
could be a result of very low concentration of cyclohexane or presence of insoluble catalyst.

The most prominent feature of this reaction is the simple separation of the catalyst and solvent from the post-reaction mixture. After carrying out oxidation using the NHPI/ $\mathrm{Co}(\mathrm{II}) / \mathrm{Fe}(\mathrm{II}) / \mathrm{CO}_{2}$ system, $\mathrm{CO}_{2}$ can be separated together with the air through degassing. When the post-reaction mixture is cooled, high quantities of catalyst (NHPI) crystallize, and the catalyst can be efficiently separated by filtration (in a recovery of $85 \%$ in the case of cyclohexane oxidation). In contrast, NHPI- $\mathrm{C}_{12}$ is completely soluble in post reaction mixture. Separation method based on extraction or adsorption must be elaborated.

\section{Conclusions}

The studies reported herein on the oxidation of cycloalkanes catalysed by $\mathrm{Co}(\mathrm{II}) / \mathrm{Fe}(\mathrm{II})$ and $N$-hydroxyimides, NHPI and NHPI-C $\mathrm{C}_{12}$, demonstrated that under $\mathrm{scCO}_{2}$ conditions $\left(0.5 \mathrm{MPa} \mathrm{O}_{2}\right.$ and $9.5 \mathrm{MPa} \mathrm{CO}$ ), higher conversion of cyclohexane and cyclooctane as well as yields of the corresponding ketone and alcohol were obtained compared to the reactions performed using air $(0.7 \mathrm{MPa})$. Additionally, the selectivity to cyclohexanol and cyclohexanone was higher in $\mathrm{scCO}_{2}$ system. High selectivity is of particular importance for the economy of the process.

The catalytic effect of NHPI on the oxidation of cycloalkanes in the presence of $\mathrm{Co}(\mathrm{II}) / \mathrm{Fe}$ (II) salts was observed only when the oxidations were carried out under $\mathrm{scCO}_{2}$. In contrast, the use of lipophilic NHPI- $\mathrm{C}_{12}$, which is more soluble in non-polar media, allows noticeably higher conversions of raw material in reactions both with and without $\mathrm{CO}_{2}$. A positive influence of the addition of NHPI or NHPI- $\mathrm{C}_{12}$ on the increase of ketone/alcohol ratio was observed. Higher yields of the ketone and alcohol were obtained when the oxidation of the cycloalkane was carried out in presence of NHPI- $\mathrm{C}_{12}$ than in the presence of the NHPI in combination with $\mathrm{Co}(\mathrm{II}) / \mathrm{Fe}$ (II) in $\mathrm{scCO}_{2}$. However, the use of the NHPI/ $\mathrm{Co}(\mathrm{II}) / \mathrm{Fe}(\mathrm{II}) / \mathrm{CO}_{2}$ system ensured the facile separation of not only the $\mathrm{CO}_{2}$ from the post-reaction mixture but also the NHPI.

Acknowledgements Financial support from the National Science Centre of Poland (OPUS 7; no. UMO-2014/13/B/ST8/04256) is gratefully acknowledged.

Open Access This article is distributed under the terms of the Creative Commons Attribution 4.0 International License (http://creativeco mmons.org/licenses/by/4.0/), which permits unrestricted use, distribution, and reproduction in any medium, provided you give appropriate credit to the original author(s) and the source, provide a link to the Creative Commons license, and indicate if changes were made.

\section{References}

Beckman EJ (2003) Oxidation reactions in CO2: academic exercise or future green processes? Environ Sci Technol 37:5289-5296. https ://doi.org/10.1021/es034540i

Chen K, Zhang P, Wang Y, Li H (2014) Metal-free allylic/benzylic oxidation strategies with molecular oxygen: recent advances and future prospects. Green Chem 16:2344-2374. https://doi. org/10.1039/C3GC42135J

Hermans I, Sakaguchi S, Nishiyama Y, Ishii Y (1996) Aerobic oxidation of alcohols to carbonyl compounds catalyzed by $\mathrm{N}$-Hydroxyphtalimide (NHPI) Combined with $\mathrm{Co}(\mathrm{acac})_{3}$. Tetrahedron Lett 36:6923-6926. https://doi.org/10.1016/00404 -0399(50)1431G

Hermans I, Van Deun J, Houthoofd K, Peeters J, Jacobs PA (2007) Silica-immobilized $N$-hydroxyphthalimide: an efficient heterogeneous autoxidation catalyst. J Catal 251:204-212. https://doi. org/10.1016/j.jcat.2007.06.025

Ishii Y, Taka Iwahama T, Sakaguchi S, Nakayama K, Nishiyama Y (1996) Alkane oxidation with molecular oxygen using a new efficient catalytic system: $N$-hydroxyphthalimide (NHPI) Combined with $\mathrm{Co}(\mathrm{acac})_{\mathrm{n}}(n=2$ or 3$)$. J Org Chem 61:4520-4526. https:// doi.org/10.1021/jo9519701

Iwahama T, Syojyo K, Sakaguchi S, Ishii Y (1998) Direct conversion of cyclohexane into adipic acid with molecular oxygen catalyzed by $N$-hydroxyphthalimide combined with $\mathrm{Mn}(\mathrm{acac})_{2}$ and $\mathrm{Co}(\mathrm{OAc})_{2}$. Org Process Res Dev 2:255-260. https://doi.org/10.1021/op980016y

Kasperczyk K, Orlińska B, Zawadiak J (2014) Aerobic oxidation of cumene catalyzed by 4-alkyloxycarbonyl- $N$-hydroxyplthalimide. Cent Eur J Chem 12:1176-1184. https://doi.org/10.2478/s1153 2-014-0565-8

Kerry Yu KM, Abutaki A, Zhou Y, Yue B, He HY, Tsang SC (2007) Selective oxidation of cyclohexane in supercritical carbon dioxide. Catal Lett 113:115-119. https://doi.org/10.1007/s10562-007-9015-y

Krzysztoforski A, Wojcik Z, Pohorecki R, Baldyga J (1986) Industrial contribution to the reaction engineering of cyclohexane oxidation. Ind Eng Chem Process Des Dev 25:894-898. https://doi. org/10.1021/i200035a010

Mayadevi S (2012) Reactions in supercritical carbon dioxide. Indian J Chem 51A:1298-1305. https://doi.org/10.1002/047084289X

Mitra M, Lloret-Fillol J, Haukka M, Costas M, Nordlander E (2013) Evidence that steric factors modulate reactivity of tautomeric ironoxo species in stereospecific alkane $\mathrm{C}-\mathrm{H}$ hydroxylation. Chem Commun 50:1408-1410. https://doi.org/10.1039/C3CC47830K

Sawatari N, Yokota T, Sakaguchi S, Ishii Y (2001) Alkane oxidation with air catalyzed by lipophilic $N$-hydroxyphthalimides without any solvent. J Org Chem 66:7889-7891. https://doi.org/10.1021/ jo0158276

Staudt S, Burda E, Giese C, Müller CA, Marienhagen J, Schwaneberg U, Hummel W, Drauz K, Gröger H (2013) Direct oxidation of cycloalkanes to cycloalkanones with oxygen in water. Angew Chem Int Ed Engl 52:2359-2363. https://doi.org/10.1002/ anie. 201204464

Suzuki Y, Harada E, Nakamaru K, Takeda Y, Sano M, Hashimoto K, Miyake T (2007) Direct oxidation of cycloalkanes with molecular oxygen to dicarboxylic acids using isoamyl nitrite. J Mol Catal A 276:1-7. https://doi.org/10.1016/j.molcata.2007.05.038

Theyssen N, Leitner W (2002) Selective oxidation of cyclooctane to cyclootanone with molecular oxygen in the presence of compressed carbon dioxide. Chem Commun. https://doi.org/10.1039/b111212k

Publisher's Note Springer Nature remains neutral with regard to jurisdictional claims in published maps and institutional affiliations. 